\title{
Surface resistance calibration for a hydrological model using evapotranspiration retrieved from remote sensing data in Nahe catchment forest area
}

\author{
WEIWEI BIE ${ }^{1}$, MARKUS C. CASPER ${ }^{1}$, PHILIPP REITER ${ }^{1} \&$ \\ MICHAEL VOHLAND ${ }^{2}$ \\ 1 Department of Physical Geography, University of Trier, Campus II, D-54286 Trier, Germany \\ s6webiee@uni-trier.de \\ 2 Geoinformatics and Remote Sensing, Institute for Geography, University of Leipzig, Johannisallee 19a, \\ D-04103 Leipzig, Germany
}

\begin{abstract}
In this paper, a method combining graphical and statistical techniques is proposed for surface resistance calibration in a distributed hydrological model, WaSiM-ETH, by comparing daily evapotranspiration simulated by model WaSiM-ETH with corresponding daily evapotranspiration retrieved from remote sensing images. The study area locates in Nahe catchment (Rhineland-Palatinate, Germany, $4065 \mathrm{~km}^{2}$ ) forest regions. The remote sensing based observations are available for a very limited number of days but representative for most soil moisture conditions. By setting canopy resistance $\left(\mathrm{r}_{\mathrm{c}}\right)$ at $150 \mathrm{~s} / \mathrm{m}$, soil surface resistance $\left(r_{\mathrm{se}}\right)$ at $250 \mathrm{~s} / \mathrm{m}$ or at $300 \mathrm{~s} / \mathrm{m}$ for deciduous forest and setting $\mathrm{r}_{\mathrm{c}}$ at $300 \mathrm{~s} / \mathrm{m}, \mathrm{r}_{\mathrm{se}}$ at $600 \mathrm{~s} / \mathrm{m}$ or at $650 \mathrm{~s} / \mathrm{m}$ for pine forest, the model exhibits its best overall performance in space and time. It is also found that with sufficient soil moisture, the model exhibits its best performance in space scale.
\end{abstract}

Key words surface resistance calibration; distributed hydrological model WaSiM-ETH; evapotranspiration; remote sensing images; soil water conditions

\section{INTRODUCTION}

The Penman-Monteith (PM) equation is widely used for evapotranspiration estimation. In the equation, surface resistance $\left(r_{s}\right)$ is a critical parameter, to which the evapotranspiration is highly sensitive, especially in dry canopy (no-rainfall) cases in forest (Beven, 1979). It is described as the bulk resistance of all transmission mediums such as crop, soil and others (Li et al., 2013). Surface resistance is difficult to specify and usually obtained from the literature or by empirical means (Farahani et al., 2007). In 1998, the Food and Agriculture Organization of the United Nations (FAO) gave a fixed surface resistance at $70 \mathrm{~s} / \mathrm{m}$ for a crop with a uniform height of $0.12 \mathrm{~m}$ (Allen et al., 1998). A further recommendation is to use a surface resistance of $50 \mathrm{~s} / \mathrm{m}$ for daytime and $200 \mathrm{~s} / \mathrm{m}$ for night-time (Allen et al., 2006). It is also recognized that surface resistance always varies between $50 \mathrm{~s} / \mathrm{m}$ and $200 \mathrm{~s} / \mathrm{m}$ for grass and $100 \mathrm{~s} / \mathrm{m}$ and $400 \mathrm{~s} / \mathrm{m}$ for forest (Rana et al., 1998). For no-rainfall conditions in forest regions, the canopy resistance $\left(r_{c}\right)$ and soil surface resistance $\left(\mathrm{r}_{\mathrm{se}}\right)$ are further defined, since actual evapotranspiration mainly comes from transpiration from plant leaves and evaporation of bare soil between plants. Interception evaporation is not taken into account due to its negligible contribution with a dry canopy.

Model performance evaluation by comparing model-simulated outputs with corresponding observations is fundamental to hydrological model calibration. For decades, remote sensing images were frequently used for hydrological state variables or heat fluxes in water cycle retrieval, especially in basins with sparse or few data available. These remote sensing based outputs are quite a popular alternative to traditional observations gauged from climate stations. They are superior to traditional observations and model simulations in the space scale, since the latter are both interpolated grid outputs whose spatial patterns depend on the locations and numbers of climate stations. However, multiple factors such as the scan cycle of satellites, the running status of the equipment and the weather conditions at the data acquisition time lead to only a limited number of high quality remote sensing images in specific time periods being available. Nouri et al. (2014) summarized that the uncertainty in aerodynamic components estimation and errors in narrow vegetation areas, such as riparian zones measurement, are also noted shortages of use of remote sensing techniques to measure evapotranspiration. 
This study proposes a method for surface resistance calibration of the WaSiM-ETH model based on a limited number of observations in time series retrieved from remote sensing images.

\section{MATERIAL AND METHODS}

\section{Study area}

The study area is Nahe catchment locating in the state of Rhineland-Palatinate, southwest Germany (Fig. 1). The River Nahe is about $120 \mathrm{~km}$ in length, rising from the Saarland and joining the River Rhine at Bingen. The drainage basin is in total $4065 \mathrm{~km}^{2}$. This area is famous for grape cultivation and quality wine production due to its moderate climate. The average elevation of the entire Nahe catchment is $353 \mathrm{~m}$ while in the north and west regions it ranges from $300 \mathrm{~m}$ to $817 \mathrm{~m}$. This area is highly wooded; deciduous forest and pine forest are the two primary forest types.

Nahe catchment has long been known as a flood prone area. Residents settle along the River Nahe and its tributaries have suffered a lot from flood damages. The recent huge flood events in this region occurred in 1993 and 1995.

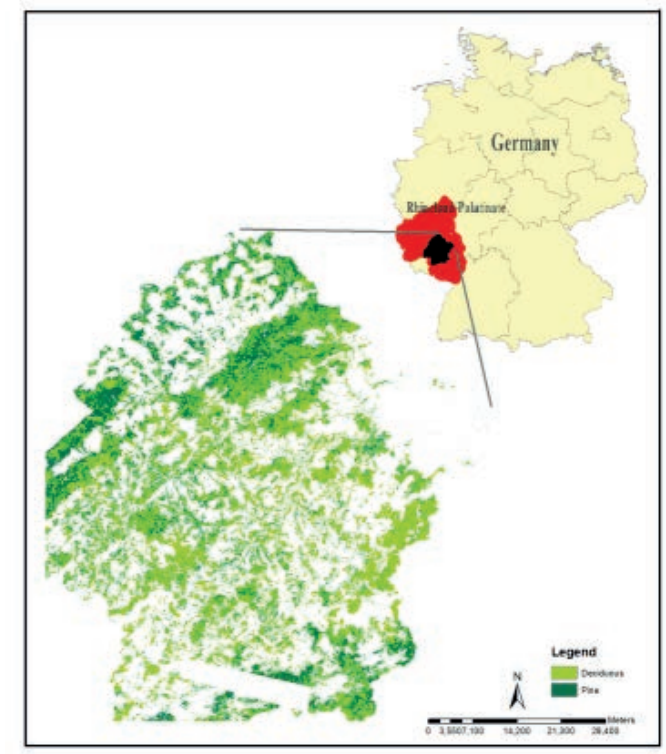

Fig. 1 Location and forest distribution of Nahe catchment

\section{Hydrological model}

WaSiM-ETH (Water Flow and Balance Simulation Model, first developed at the ETH Zurich in Switzerland) is a distributed, deterministic, mainly physical and grid-based hydrological model (Schulla and Jasper, 2007). In this study, a long-term simulation from 1971 to 2003, with a daily time step, was conducted. Meteorological data such as sunshine duration, air temperature, relative humidity, wind speed and precipitation selected from 15 climate stations were employed. The potential evapotranspiration (ETP) was first estimated by the Penman-Monteith approach (Monteith, 1975, Brutsaert, 1982). The formulation is:

$$
\lambda E=\frac{3.6 \cdot \frac{\Delta}{\gamma_{p}}\left(R_{n}-G\right)+\frac{\rho \cdot C_{p}}{\gamma_{p} \cdot r_{a}}\left(e_{s}-e\right) \cdot t_{i}}{\frac{\Delta}{\gamma_{p}}+1+r_{s} / r_{a}}
$$

where $\lambda$ is the latent vaporization, $\mathrm{E}$ is the latent heat flux, $\Delta$ is the tangent to the saturated vapour pressure curve, $R_{n}$ is the net radiation, $G$ is the soil heat flux, $\rho$ is the density of dry air, $C_{p}$ is the specific heat capacity of dry air at constant pressure, $\mathrm{e}_{\mathrm{s}}$ is the saturation vapor pressure at temperature $T, e$ is the actual vapour pressure, $t_{i}$ is the number of seconds within a time step, $\gamma_{p}$ is the psychrometric constant, $r_{s}$ is the bulk-surface resistance and $r_{a}$ is the bulk-aerodynamic resistance. 
In the model, transpiration from plants and evaporation from bare soil were separately calculated by equation (1). Canopy resistance $\left(\mathrm{r}_{\mathrm{sc}}\right)$ and soil surface resistance $\left(\mathrm{r}_{\mathrm{se}}\right)$ are the separate corresponding surface resistances. According to the actual soil moisture, actual evapotranspiration (ETA) was then obtained based on ETP. All soil water conditions are considered:

$$
\begin{array}{ll}
\operatorname{ETA}_{i}=0 & \Theta(\psi)<\Theta_{w p} \\
\operatorname{ETA}_{i}=\operatorname{ETP}_{i} \cdot\left(\Theta\left(\psi_{i}\right)-\Theta_{w p}\right) /\left(\Theta_{\psi_{g}}-\Theta_{w p}\right) & \Theta_{w p} \leq \Theta(\psi) \leq \Theta_{\psi_{g}} \\
\operatorname{ETA}_{i}=\operatorname{ETP}_{i} & \Theta(\psi) \leq \eta \cdot \Theta_{\text {sat }} \\
\operatorname{ETA}_{i}=\operatorname{ETP}_{i} \cdot\left(\Theta_{\text {sat }}-\Theta\left(\psi_{i}\right)\right) /\left(\Theta_{\text {sat }}-\eta \cdot \Theta_{\text {sat }}\right) & \eta \cdot \Theta_{\text {sat }}<\Theta(\psi) \leq \Theta_{\text {sat }}
\end{array}
$$

where $i$ is the index of the soil layer, $\Theta(\psi)$ is the actual relative soil water content at suction $\psi$, $\eta$ is the maximum relative soil water content without partly or totally anaerobic conditions, $\Theta_{\text {sat }}$ is the saturation water content of the soil, $\Theta_{\psi_{\mathrm{g}}}$ is the soil water content at a given suction $\psi_{\mathrm{g}}$, $\Theta_{\mathrm{wp}}$ is the soil water content at the permanent wilting point.

\section{Remote sensing}

A modification of simplified method is used for daily evapotranspiration estimation by remote sensing images. The simplified method was firstly proposed by Jackson et al. (1977), in which the sensible heat flux is linearly related to the instantaneous temperature difference between surface and air at midday with a constant B, as well as the integrated daily soil heat flux is considered as negligible. Based on the surface energy equation, evapotranspiration is obtained as its energy consumption - the latent heat flux, by subtracting sensible heat flux from net radiation. This method has been improved by a number of studies (Sequin and Itier, 1983; Nieuenhuis et al., 1985; Carlson et al., 1995). An additional exponential coefficient $\mathrm{n}$ and a non-constant $\mathrm{B}$ are finally employed to retrieve sensible heat flux from surface-air temperature difference. Moreover, both $\mathrm{n}$ and $\mathrm{B}$ are given as functions of fractional vegetation cover. Casper and Vohland (2008) further considered the contribution of soil heat flux and modified the method as:

$$
\int_{0}^{24 h} L E=\int_{0}^{24 h} R_{n}-G-B\left(T_{s(\max )}-T_{a(\max )}\right)^{n}
$$

where $\int_{0}^{24 h} L E$ is the daily latent heat flux for 24 hours, $R_{n}$ is the daily net radiation for 24 hours, $\mathrm{G}$ is the soil heat flux, $\mathrm{T}_{\mathrm{s}(\max )}$ is the daily maximal land surface temperature, $\mathrm{T}_{\mathrm{a}(\max )}$ is the daily maximal near surface air temperature, parameter $\mathrm{B}=0.0109+0.051 \mathrm{f}_{\text {cov }}$, parameter $\mathrm{n}=$ $1.067-0.372 \mathrm{f}_{\text {cov }}$, with $\mathrm{f}_{\text {cov }}$ is the fractional vegetation cover.

High quality Thematic Mapper (TM) images and Enhanced Thematic Mapper plus (ETM+) images from five separate dates (15 May 2000, 5 July 2001, 19 July, 4 August and 21 September in 2003) were selected from the time period that model run (1971-2003). The summer of 2003 is known as extremely warm and dry in Germany. Bands $1-5$ and 7 of both TM and ETM+ images with a spatial resolution of $30 \mathrm{~m}$ were used for a series of surface properties achieving: surface albedo, normalized difference vegetation index (NDVI), fractional vegetation cover $\left(\mathrm{F}_{\mathrm{cov}}\right)$ and surface emissivity coefficient. Thermal band 6 with a resolution of $120 \mathrm{~m}$ for TM and $60 \mathrm{~m}$ for $\mathrm{ETM}+$ were applied for land surface temperature (LST) retrieving.

In the following we use "ET" to denote the evapotranspiration simulated from WaSiM-ETH model and "LE" to denote the corresponding evapotranspiration retrieved by remote sensing images. All text, figures and tables will follow this rule.

\section{Model performance evaluation}

Mean absolute error (MAE) and root mean square error (RMSE) are two similar and widely used measures in model performance evaluation, smaller values of which indicate less mean gross error between two variables. MAE is less sensitive to extreme values compared to RMSE (Fox, 1981) and avoids the physically artificial exponentiation that RMSE has (Willmott, 1982). Willmott and Matsuura (2005) concluded that RMSE is an inappropriate and misinterpreted measure of average 
model performance error while MAE is more natural and unambiguous. In this paper, MAE were employed and calculated as:

$$
M A E=\frac{1}{n} \sum_{i=1}^{n}\left|e_{i}\right|
$$

where $e_{i}(i=1,2,3 \ldots n)$ indicates pixel-wise difference between ET and LE.

\section{RESULTS AND DISCUSSION}

\section{Temporary pattern}

For both forest types, LE at five dates shows similar patterns in time scale (Fig. 2): (1) on 5 July 2001, the median of LE is the top of all, (2) median LE on 19 July 2003 is higher than that on 15 May 2000 and decreases sharply to 4 August 2003, (3) on 21 September 2003 the median LE is the lowest. It is noted that the very low actual evapotranspiration on 4 August 2003 shows a high contrast to those amounts on 5 July 2001 and 19 July 2003, which are also in summer time. For deciduous forest, two ET groups with surface resistance combinations of $r_{\mathrm{sc}}$ at $150 \mathrm{~s} / \mathrm{m}, \mathrm{r}_{\mathrm{se}}$ at 250 $\mathrm{s} / \mathrm{m}$, and $\mathrm{r}_{\mathrm{sc}}$ at $150 \mathrm{~s} / \mathrm{m}, \mathrm{r}_{\mathrm{se}}$ at $300 \mathrm{~s} / \mathrm{m}$ (separately denoted as ET group 150_250 and ET group 150300 , notation of ET groups with different surface resistance combinations follows the same rule) show similar temporary patterns (Fig. 2(a)). Four groups of ET 300_600, ET 300_650, ET 300_750 and ET 350_600 for pine forest exhibit similar temporary patterns (Fig. 2(b)) to LE.
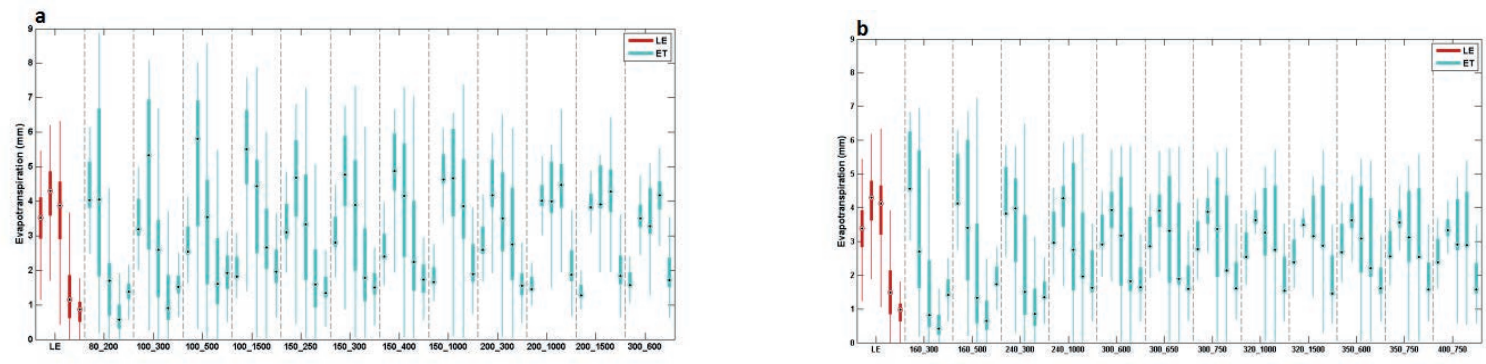

Fig. 2 Daily evapotranspiration at five dates (in mm, including both LE and ET, with five days each group) in (a) deciduous forest and (b) pine forest. The red boxplots are one LE group as well as the 12 green boxplot groups from ET groups simulated with 12 different surface resistance combinations by WaSiM-ETH. The five sample dates are 15 May 2000, 5 July 2001, and 19 July, 4 August and 21 September 2003, in order.

\section{Model performance}

For deciduous forest, five day's MAE between ET 150_250 and LE and five day's MAE between ET 150_300 and LE (denoted as MAE group 150_250 and MAE group 150_300, denotation of other MAE groups between ET with different surface resistance combinations and LE follow the same rule) indicate relatively better overall model performance (than others) - the MAE of five days are all in relatively small ranges (below the horizontal reference line, Fig. 3(a)). Likewise, groups of MAE 300_600 and MAE 300_650 indicate better overall model performance in time scale for pine forest (Fig. $3(\mathrm{~b})$ ).
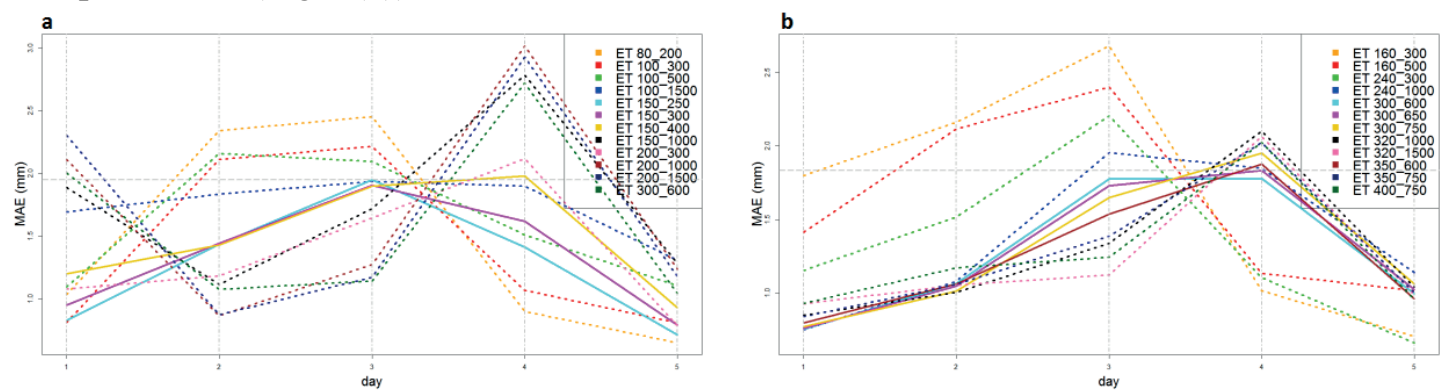

Fig. 3 Five-days MAE (mean absolute error) between ET (simulated from 12 surface resistance combinations) and LE in (a) deciduous forest and (b) pine forest. 


\section{Soil water content}

In this paper, we assumed that daily soil water content simulated by WaSiM-ETH model with the surface resistance, which the minimal MAE indicates, approaches the reality of that day. With this assumption, the approximate actual soil water content of five separate days in both forest types are roughly inferred (Fig. 4). It is shown that in both forest types, it was wet but unsaturated (the saturated water content point is set as $95 \%$ in WaSiM-ETH) on 15 May 2000 when relative soil moisture was mainly distributed in an approximate range from $80 \%$ to $91 \%$; 5 July 2001 and 19 July 2003 were medium wet since their soil moisture roughly ranges from $40 \%$ to $89 \%$; on 4 August and 21 September 2003 the soil moistures were mainly in the range 35\% to 55\%, which is really dry.
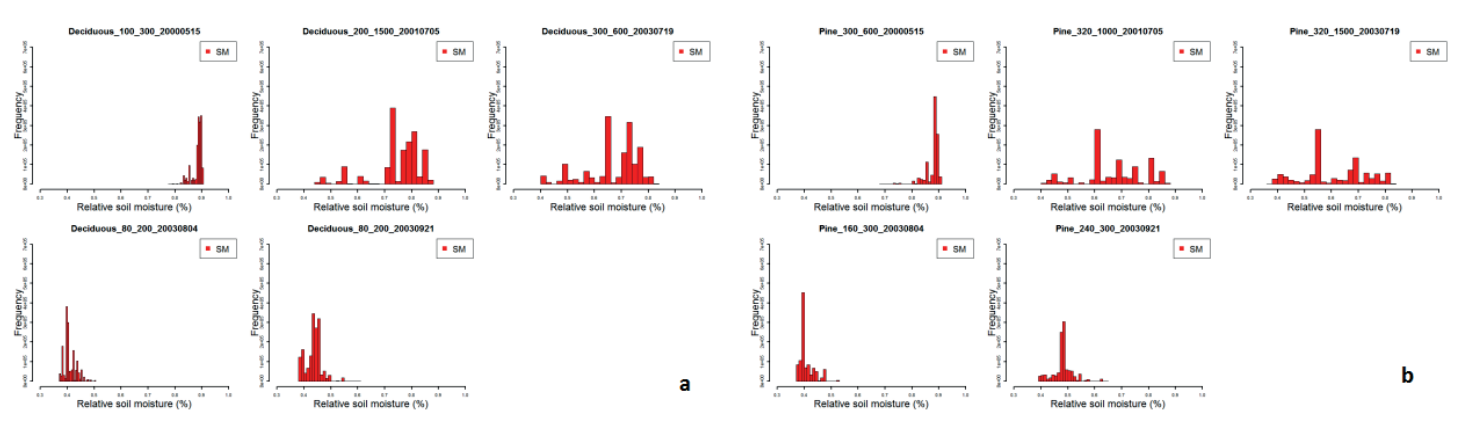

Fig. 4 Five days' inferred roughly actual relative soil moisture in root zone in (a) deciduous forest and (b) pine forest.
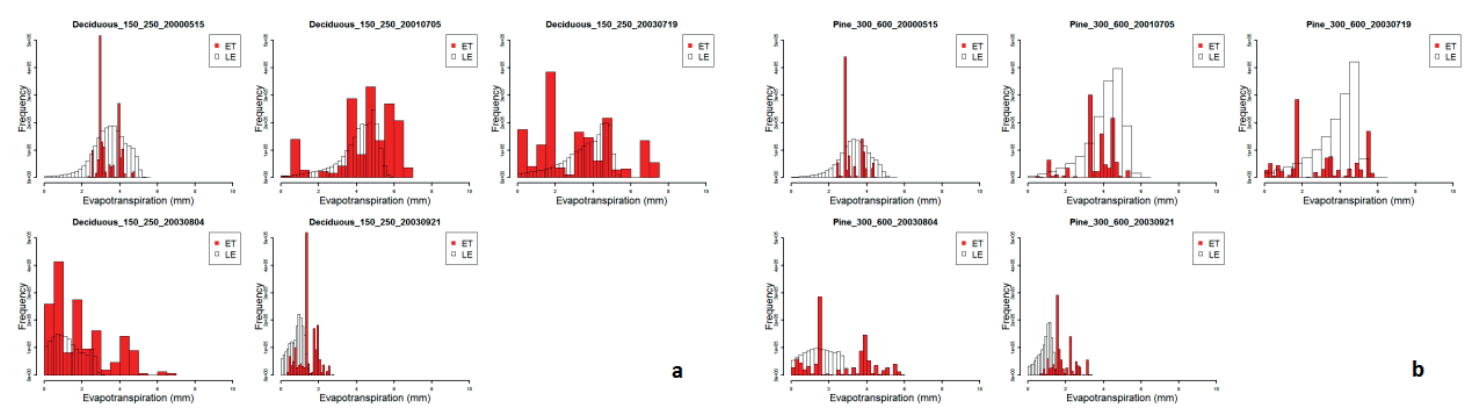

Fig. 5 Five days' frequency distribution of (a) ET 150_250 and LE in deciduous forest and (b) ET 300_600 and LE in pine forest.

As the principal reference while reducing potential evapotranspiration (ETP) to actual evapotranspiration (ETR), actual soil water content determines the magnitude of ET generation. It is also inferred to affect the daily ET performance in the space scale (Fig. 5): ET with sufficient soil water (on 15 May) performs best - including smaller MAE and non-bias error trend, while ET with less soil moisture (on 4 August and 21 September) leads also to lower MAE but obviously to an overestimation. Therefore it is also inferred that ET with a single soil moisture condition (mainly wet or dry unlike that on 5 July and 19 July) exhibits less average gross error. Daily LE and ET show very different spatial distribution (Fig. 5) - the former is continuous while the latter is discontinuous.

\section{CONCLUSION}

A method combining graphical and statistical techniques for surface resistance calibration in WaSiM-ETH was proposed in this paper. Model performance in both time and space scale have been assessed. Boxplots were used to visually evaluate the temporary similarity between simulations and observations, especially for the extremely event (on 4 August 2003). MAE is employed to measure the daily spatial errors between the paired data sets. Considering multiple soil water conditions, this method covers the shortage of observations retrieved from remote 
sensing images, i.e. limited numbers of discontinuous data in a specific time period are available. Soil moisture is inferred to be a critical factor affecting model performance. With sufficient soil moisture, the model simulated ET leads to better performance in the space scale with less average gross error and non-bias error trend. By setting canopy resistance $\left(\mathrm{r}_{\mathrm{sc}}\right)$ at $150 \mathrm{~s} / \mathrm{m}$ and soil surface resistance $\left(\mathrm{r}_{\mathrm{se}}\right)$ at $250 \mathrm{~s} / \mathrm{m}$ or at $300 \mathrm{~s} / \mathrm{m}$ for deciduous forest, as well as setting $\mathrm{r}_{\mathrm{sc}}$ at $300 \mathrm{~s} / \mathrm{m}$ and $\mathrm{r}_{\mathrm{se}}$ at $600 \mathrm{~s} / \mathrm{m}$ or at $650 \mathrm{~s} / \mathrm{m}$ for pine forest, comparing ET with LE visually shows similar temporary patterns and statistically exhibits better overall model performance in time and space scale.

Acknowledgement This work integrated datasets and methods in both remote sensing and hydrological model. We are grateful to staff in the Physical Geography Department and Remote Sensing Department of University Trier. We also appreciate our former colleagues, Oliver Schmidt, Gayaneor Grigoryan and Alina Schmidt, for their help and contributions.

\section{REFERENCES}

Allen, R.G., et al. (1998) Crop Evapotranspiration: Guidelines for computing crop water requirements. FAO Irrigation and drainage paper 56. FAO, Rome 300, 6541.

Allen, R.G., et al. (2006) A recommendation on standardized surface resistance for hourly calculation of reference ET $_{0}$ by the FAO56 Penman-Monteith method. Agricultural Water Management 81(1), 1-22.

Beven, K. (1979) A sensitivity analysis of the Penman-Monteith actual evapotranspiration estimates. Journal of Hydrology 44(3), 169-190.

Brutsaert, W. (1982) Evaporation into the Atmosphere. Kluwer Academic Publishers, Dordrecht.

Carlson, T.N., Capehart, W.J., and Gillies, R.R. (1995). A new look at the simplified method for remote sensing of daily evapotranspiration. Remote Sensing of Environment 54(2), 161-167.

Casper, M. C. and Vohland, M. (2008) Validation of a large scale hydrological model with data fields retrieved from reflective and thermal optical remote sensing data - A case study for the Upper Rhine Valley. Physics and Chemistry of the Earth, Parts $A / B / C$ 33(17), 1061-1067.

Farahani, H.J., et al. (2007) Evapotranspiration: progress in measurement and modeling in agriculture. Trans. ASABE 50(5), $1627-1638$

Fox, D.G. (1981). Judging air quality model performance. Bulletin of the American Meteorological Society 62(5), 599-609.

Jackson, R.D., Reginato, R.J. and Idso, S.B. (1977) Wheat canopy temperature: a practical tool for evaluating water requirements. Water Resources Research 13(3), 651-656.

Li, S., et al. (2013). Quantifying the combined effects of climatic, crop and soil factors on surface resistance in a maize field. Journal of Hydrology 489, 124-134.

Monteith, J.L. (1975) Vegetation and the Atmosphere, vol. 1: Principles. Academic Press, London.

Nouri, H., et al. (2014) Remote sensing techniques for predicting evapotranspiration from mixed vegetated surfaces. Hydrology and Earth System Sciences Discussions, 10(3).

Rana, G. and Katerji, N. (1998) A measurement based sensitivity analysis of the Penman-Monteith actual evapotranspiration model for crops of different height and in contrasting water status. Theoretical and Applied Climatology 60(1-4), 141-149.

Schulla, J. and Jasper, K. (2007) Model Description WaSiM-ETH. Institute for Atmospheric and Climate Science. Swiss Federal Institute of Technology, Zürich.

Seguin, B. and Itier, B. (1983) Using midday surface temperature to estimate daily evaporation from satellite thermal IR data. International Journal of Remote Sensing 4(2), 371-383.

Willmott, C.J. (1982) Some comments on the evaluation of model performance. Bulletin of the American Meteorological Society 63(11), 1309-1313.

Willmott, C.J. and Matsuura, K. (2005) Advantages of the mean absolute error (MAE) over the root mean square error (RMSE) in assessing average model performance. Climate Research 30(1), 79. 